to attend courses in any subject. Nor is his criticism of "the absence of suitable text books" particularly valid, while his concern with "expensive microscopes and micro-projectors" as "a sine qua non of effective work" suggests a limited and specialist approach. It may be questioned, too, whether the claim that "the same objective methods" are used in the social sciences as in the physical can altogether be justified, while the criticism that the scientist is not necessarily dispassionate in his political or sociological judgments does not get us far: few of us would care to make even academic philosophers our kings.

Yet Prof. Peers offers some useful suggestions as to the development of courses in the sciences, and puts the subject in its proper perspective by proposing the establishment of science sub-departments of extra-mural departments, with the aim, above all, of achieving "the reintegration of science as an indispensable part of a liberal education". As a nonscientist he has rendered a valuable service in opening the subject for discussion : it is to the scientists in adult education that we now look for a more developed statement.

\section{NUTRITION AND THE LIVER SYMPOSIUM IN GLASGOW}

$\mathrm{O}$ May 8 the Scottish Group of the Nutrition Society held a symposium on "Nutrition and the Liver" in the Biochemistry Department of the University of Glasgow under the chairmanship of Prof. J. N. Davidson, head of the Department. This meeting provided an opportunity for workers in fields ranging from academic biochemistry to clinical medicine to pool their knowledge. Prof. Davidson introduced the subject with a short paper entitled "The Chemical Architecture of the liver Cell", in which he described the technique of differential centrifugation, by means of which liver cells may be separated into a nuclear fraction, mitochondria, microsomes and the cell sap. He pointed out that mitochondria isolated in this way are morphologically different from mitochondria as seen in the living cell ; furthermore, they are not a homogeneous population, since they can be subdivided into several chemically and enzymologically distinct fractions. The microsomal fraction is composed of minute particles, but these may represent the disintegration products of a reticulum in the cytoplasm of the living cell. Prof. Davidson then demonstrated that, although most chemical constituents of the liver are considerably affected by variations in nutritional status, the total amount of one component, deoxyribonucleic acid, remains unchanged even in the face of extreme dietary variations; the quantity of this component is determined solely by the number of cells present. Consequently, deoxyribonucleic acid can be used as a reference standard against which changes in other liver cell constituents can be measured. Examples were given of the misleading results which may be obtained when liver composition is expressed per $100 \mathrm{gm}$. of fresh tissue, and the clarification in interpretation which follows the expression of results in relation to deoxyribonucleic acid.

The influence of the protein and energy content of the diet on liver composition was considered by $\mathrm{Dr}$. H. N. Munro (Department of Biochemistry, Glasgow).
The amount of protein in the liver is considerably affected both by the level of protein and of energy intake. These changes in protein content occur much more rapidly and extensively in the liver than in most other tissues of the body. This has led to the supposition that the liver may contain a store of protein which is readily depleted under adverse nutritional conditions; but attempts to demonstrate a chemically discrete storage protein have not met with success. In parallel with changes in the protein content of the liver, there are also variations in ribonucleic acid and phospholipid content. These changes occur without any alteration in cell number, and the material so gained or lost has been named "labile liver cytoplasm" (Kosterlitz). By means of differential centrifugation of the liver into fractions, it has been shown that a reduction in protein intake causes a loss of protein from all parts of the liver cell, of ribonucleic acid principally from the microsomes, and of phospholipid from the microsomes and cell sap. Thus the material lost from various parts of the liver cell is not uniform in composition. Although the amount of ribonucleic acid is reduced by protein deficiency, its rate of synthesis seems to be independent of protein intake and to be determined by the level of energy intake. Dr. Munro concluded by suggesting that the failure to identify the labile protein of the liver with any single chemical or morphological entity within the liver cell could be readily explained if differences in the rates of protein synthesis in different tissues are considered. Such differences in rate will determine the speed with which these tissues adjust their protein content to altered dietary conditions. The liver, being among the most active in protein synthesis, will become rapidly adjusted, giving the impression of gaining or losing a labile protein component.

Dr. J. M. Naftalin (Rowett Research Institute) dealt with the production of liver necrosis in rats by dietary means. In summarizing the history of this subject, he pointed out that the two dietary conditions generally believed to be necessary for the production of liver necrosis are deficiency of sulphurcontaining amino-acids and lack of vitamin $\mathrm{E}$. His own investigations were aimed at determining the influence of restriction of food intake and of environmental temperature on the incidence of liver necrosis among animals receiving necrogenic diets. $\mathrm{He}$ observed that $70-78^{\circ} \mathrm{F} .\left(21 \cdot 1-25 \cdot 6^{\circ} \mathrm{C}\right.$. $)$ is the optimal temperature for producing necrosis on diets deficient in vitamin $\mathrm{E}$ and low in sulphur-containing amino-acids, the incidence being considerably less at temperatures higher or lower than this. In addition, caloric restriction with the same diet reduces the frequency of necrosis. A sufficient degree of food restriction prevents liver necrosis at all environmental temperatures, but too severe restriction leads to death without necrosis. Variations in the incidence of necrosis also occur when different preparations of casein are used as the protein source in the necrogenic diet. The incidence of necrosis was found to depend on the origin of the casein and to be independent of alcohol--ether treatment used for the removal of vitamin contaminants. It is not yet known whether caseins differ in necrogenicity because of the presence of a toxic factor in the high-incidence preparations or of a protective factor in the lowincidence preparations.

Dr. E. Kodicek (Dunn Nutritional Laboratory, Cambridge) contributed a paper on the storage of vitamins in the liver which summarized much recent 
work on the subject. He defined storage as the amount of a particular vitamin laid down in excess of the physiological level needed for normal functioning. From this point of view, the vitamins fall into two classes. The first group comprises those which occur in coenzymes or the prosthetic groups of enzymes, and for this group Dr. Kodicek proposed the name 'prosthetins'. Even with massive dosage, their concentration in the liver does not exceed a certain limit which probably represents saturation of the apoenzyme with the prosthetic group. Deficiency reduces the amount in the liver, but never to very low levels. These features are to be contrasted with the behaviour of the other group, the fat-soluble vitamins. Their concentration in the liver can be enormously increased by dosage (for example, to a hundred times the physiological level) or reduced to virtually zero by deficiency. The pattern of storage varies for the different fat-soluble vitamins. On dosage with vitamin A the efficiency of utilization can reach a maximum of 80 per cent of the amount fed, very high doses being toxic and leading to less efficient storage. By contrast, only a small fraction of administered vitamin $D$ is stored in the body, most of it in the liver. Vitamin $\mathrm{E}$ is mainly found in the body fat; but dosage with this vitamin leads to a temporary increase in the liver concentration. It has recently been shown by Dam and his colleagues that deposition of vitamin $\mathrm{K}$ in the livers of chicks occurs only in response to dosage with the natural vitamin and not after administration of vitamin $\mathrm{K}$ substitutes; this may have therapeutic importance.

Dr. J. Waterlow (University College of the West Indies) described his experiences with disorders of the liver found in tropical countries in association with malnutrition. The chief forms of liver disease which are common in tropical climates are fatty liver and cirrhosis ; massive necrosis is not more frequent than elsewhere. Fatty liver is found in very young children, and a severe form of fatty liver is a prominent feature of the kwashiorkor syndrome. The condition is nutritional in origin, probably the result of protein malnutrition in particular. In cases of fatty liver there is evidence of protein depletion, and Dr. Waterlow made the point that stigmata of protein insufficiency are not limited to the liver but are generalized, the organs most severely affected being those with the highest turnover of protein. Deposition of fat in the liver does not appear to be the fundamental factor determining the severity of the disease, which is probably dependent on the degree of protein depletion. The other common tropical liver condition, eirrhosis, does not appear to be an end-result of fatty infiltration, as has been demonstrated experimentally in rats. Geographically, there is little correspondence between the incidence of juvenile cirrhosis and of fatty livers in tropical countries. Dr. Waterlow suggested that juvenile cirrhosis may be produced by a combination of factors, one of which is malnutrition. Thus the occurrence of cirrhosis among West African children may result from a combination of malaria and malnutrition, the malnutrition being responsible for damage to the parenchymal cells and the malaria for overgrowth of fibrous tissue. In the West Indies the combination may be one of malnutrition and dietary toxins, arising from the widespread use of decoctions of plants ('bush tea').

The place of diet in the treatment of liver disease was discussed by Dr. A. L. Latner (Department of
Chemical Pathology, Royal Victoria Infirmary, Newcastle upon Tyne), who described the nutritional principles underlying such treatment. $\mathrm{He}_{\Theta}$ pointed out that, while a generous supply of protein in the diet is desirable for the regeneration of liver cells after the acute phase of liver damage is ended, the intravenous use of protein hydrolysates is irrational since the blood during severe liver damage already contains excessive amounts of amino-acids. There is, however, a good case for giving ample amounts of the vitamins. An interesting point made by Dr. Latner in this connexion was that the macrocytic anæmia associated with liver disease is relieved by folic acid but not by vitamin $B_{12}$. He also emphasized that liver diseases often cause profound disturbances of electrolyte metabolism which require correction. In acute liver failure Dr. Latner has obtained a high recovery rate by the intravenous use of glucose, saline, potassium chloride and massive doses of thiamine, nicotinamide and riboflavine, together with intramuscular injections of vitamins $\mathrm{E}$ and $\mathrm{K}$. The dietetic treatment of some less acute forms of liver disease was also described.

Dr. A. J. Hale provided a microscopical demonstration of the minute anatomy of the liver for those attending the meeting. The communications will be published in the Proceedings of the Nutrition Society.

H. N. MunRo

\section{THIRD INTERNATIONAL RUBBER TECHNOLOGY CONFERENCE}

$\mathrm{T}$ THE Third International Rubber Technology Conference, held in London at Church House, Westminster, during June 22-25, under the auspices of the Institution of the Rubber Industry, was attended by some six hundred and twenty delegates from eighteen countries. About seventy-five of the delegates were accompanied by their wives, for whom a separate social programme of visits to places of interest had been arranged.

In declaring the Conference open, its patron, the Marquess of Salisbury, who was introduced by the president of the Institution of the Rubber Industry, Lord Baillieu, welcomed the delegates on behalf of the British Government. He recalled that it was six years since the last Conference of this type, and that the matters to be discussed interested many parts of the world and would be concerned with such important matters as synthetic rubber, combinations of synthotic with natural rubber, and chemical modifications of natural rubber itself. After the official opening, the chair was taken by Dr. W. J. S. Naunton, the chairman of the Conference, who announced that there would be in all seven sessions, each having its sectional chairman, who would be a well-known authority on the subjects to be discussed. Fifty papers covering a wide range of subjects, some highly scientific and others purely technological, had been pre-printed and already circulated to the delegates. These papers had been selected from the ninety offered as being likely to provide a source of stimulating discussion.

The first session, under the chairmanship of Mr. E. A. Murphy, consisted of eight papers on the properties of natural rubber latex. The subjects discussed included the variability of Hevea latex, with 